\title{
Convite à Viagem, ou Como o Cinema Português Constrói as suas Paisagens
}

FILIPA ROSÁRIO

Universidade de Lisboa

\begin{abstract}
In the present article, I consider five different relations between character and landscape/setting in the context of Portuguese cinema produced between the 1960s and the 2000s. To achieve this, I examine ten Portuguese films produced between 1963 and 2009. Through a close analysis of these ten films, I show how landscape serves to project, within a particular current of Portuguese cinema, both social and historical grounds into an aesthetic dimension.
\end{abstract}

Keywords: Portuguese cinema; landscape; aesthetics; space; Veredas

Este artigo propõe averiguar dinâmicas de paisagem no cinema português através da análise de filmes edificados a partir do espaço geográfico onde a ação decorre. Neles, os espaços, rural ou urbano, progressivamente adquirem força narrativa visual e simbólica, impondo-se enquanto paisagem a contemplar-se, sem deixar de operar enquanto cenário. Partindo da distinção teórica entre cenário e paisagem cinematográficos, serão extraídas cinco modalidades diferentes dos filmes analisados, no que respeita à relação entre a personagem e o espaço. Posteriormente, serão mapeadas afinidades entre protagonistas e experiências de lugar tomando como referentes essas modalidades, para compreender que filmes resistem à organização e de que forma o fazem.

Analisa-se os filmes Acto da primavera (1963) e Vale Abraão (1993) de Manoel de Oliveira, Os verdes anos (1963) e O rio do ouro (1998) de Paulo 
Rocha, Belarmino (1964) de Fernando Lopes, Veredas (1978) e À flor do mar (1986) de João César Monteiro, Trás-os-Montes (1976) de António Reis e Margarida Cordeiro, O fantasma (2000) de João Pedro Rodrigues e Ruínas (2009) de Manuel Mozos. Tais obras expõem partes do território geográfico português, redefinindo esses espaços concretos no processo de exposição. Fazem-no de formas diferenciadas, sendo que todos eles deixam descobertas dimensões reservadas e obscuras dos locais que retratam. Além disso, são filmes que regeneram a imagem cinematográfica das regiões e das cidades filmadas. Seja por via de um gesto estetizante consciente ou por via da ação da personagem que transforma o espaço que habita, fazendo com que o contemplemos como um mundo novo, todas estas obras partilham o efeito recriador de paisagens portuguesas no cinema.

\section{Algumas notas sobre paisagem e cinema}

Enquanto construção, o conceito de paisagem pressupõe um sujeito que habita e/ou observa um determinado território geográfico. Nas palavras de Inês Sapeta Dias:

A paisagem tanto resulta de um processo de individuação - uma paisagem não é a natureza toda, mas uma vista limitada sobre o todo natural, resultando de uma relação específica com este; daí poder dizerse uma paisagem, mas só a natureza -; como resulta de um processo de ordenamento, que inclui a ideia de composição (criação de ligações e arranjos entre os elementos incluídos nesse quadro ou vista) e a definição de um lugar de onde ver ou de um ponto de vista. (283)

Segundo Sapeta Dias, o enquadramento, a composição e a perspetiva são inerentes ao conceito de paisagem, assim como a noção de recorte espacial, sendo que nessa parcela de espaço se intui a ideia de infinito a ser contemplado. Sobre a relação entre paisagem e pintura, no âmbito da qual a primeira surge, afirma Anne Cauquelin:

Tomada apenas no contexto da pintura, a paisagem restituir-se-ia, pois, a uma representação figurada, destinada a seduzir a visão do espectador 
através da ilusão perspetivista. A inesgotável riqueza dos elementos naturais encontraria um local privilegiado, o quadro, para surgir na harmonia enquadrada de uma forma e incitaria, então, a interessar-se por todos os aspetos da Natureza, como por uma realidade à qual o quadro daria acesso. (28)

Tanto a palavra quanto o conceito paisagem revelam um ponto de vista autoral por via do enquadramento. Esse segmento de espaço natural encontra-se disposto na tela segundo uma ordem ditada, sobretudo, pelas regras da perspetiva. Portanto, desde a sua génese a paisagem é um conceito subjetivo e visual, e permite leituras multidisciplinares daquele espaço/lugar, daquela representação de espaço/lugar porque resulta do olhar de quem a retrata e de quem a contempla (Rosário e Álvarez 58).

Da perspetiva da narrativa fílmica, a questão da edificação da paisagem a partir do cenário pode ser pensada em termos da autonomia do espaço filmado relativamente à ação. Martin Lefebvre distingue duas formas de atividade por parte do espectador na experiência do visionamento: o modo narrativo e o modo "espetacular" (28). O modo narrativo fixa-se na atenção dada à ação do filme, o "espetacular" na contemplação e reação à "visualidade" do filme enquanto espetáculo (Lefebvre 56). Assim, este modo "espetacular" alterna com o modo narrativo no decurso do visionamento e, quando o foco deixa de estar na ação que dinamiza a narrativa, surge então a contemplação:

When I contemplate a piece of film, I stop following the story for a moment, even if the narrative does not completely disappear from my consciousness - to which I may add that is precisely because the narrative does not disappear from my consciousness that I can easily pick it up again. The interruption of the narrative by contemplation has the effect of isolating the object of the gaze, of momentarily freeing it from its narrative function. Said differently, the contemplation of filmic spectacle depends on an "autonomizing" gaze. It is this gaze which enables the notion of filmic landscape in narrative fiction (and eventbased documentary) film; it makes possible the transition from setting to landscape. (Lefebvre 29) 
A mise-en-scène no cinema narrativo português testa a arrumação teórica de Lefebvre no sentido em que a mise-en-scène tende a dilatar o tempo, integrar o silêncio, excluir a ação física. A câmara tende a estar parada, as personagens geralmente são caladas e as cenas lentas. Os realizadores portugueses trabalham o temps-mort, que Barthes define como a extensão da insistência no poder do olhar por parte de todos os artistas visuais a propósito do cinema de Antonioni, e que quebra a convenção narrativa, perturba assim a ordem estabelecida, e subverte a norma (9). Ou seja, o cinema português recorre a mecanismos que potenciam a alteração do olhar do espectador para o modo "espetacular," estetizante, para além de desestabilizarem a linearidade e continuidade narrativas.

\section{Personagens e espaços}

$\mathrm{Na}$ análise dos filmes que atrás referi, extraí cinco ligações distintas entre personagem e espaço: 1) a personagem "des-cobre" o espaço, deixando-o descoberto; 2) a personagem transforma o espaço, recriando-o; 3) a personagem funde-se com o espaço; 4) o espaço "des-cobre" a personagem, revelando-a; e 5) o espaço aprisiona a personagem.

Desta forma, vê-se a primeira ligação entre personagem e espaço quando os protagonistas de Os verdes anos, Trás-os-Montes, Veredas e Belarmino revelam o território geográfico português nos seus périplos diários. Retratam-no na sua modernidade urbanística, no caso de Lisboa no filme de Rocha; na intangibilidade espectral de uma ruralidade em desaparecimento no de Reis e Cordeiro; na "con-fusão" de universos culturais díspares e de regiões geográficas portuguesas no filme de César Monteiro, e, por fim, no ininterrupto movimento urbano de uma Lisboa popular, decadente mas nobre, no filme de Lopes.

Por seu lado, a segunda ligação aparece com o protagonista de $O$ fantasma e a recriação do bairro lisboeta de Alvalade, como se tratasse de um superherói. João Pedro Rodrigues filma Alvalade de noite, apresentando-o como um submundo obscuro e fetichista, abrindo espaço à homossexualidade masculina na imagem de Lisboa no cinema. No filme de Mozos, as vozes sem corpo que habitam aquelas ruínas dotam de pathos os espaços vazios, levando a que ali se encenem várias histórias invisíveis de forma elíptica, e a que, 
consequentemente por via da sugestão, se reconheçam nos escombros histórias de vidas passadas. Por outro lado, na estrutura em mise en abyme de Acto da primavera, Oliveira revela o dispositivo cinematográfico ao incluir na montagem final um plano breve consigo mesmo em campo, enquanto realizador de um filme sobre uma encenação teatral — Oliveira a filmar o teatro. Esta subtil autofiguração torna-o protagonista do filme, uma etnoficção autorreflexiva reveladora de uma paisagem documental (antropológica), mítica (bíblica) e teórico-discursiva (meta-cinematográfica).

Já a terceira ligação está em Ema de Vale Abraão, ao confundir-se com a paisagem do vale do Douro. No mundo aristocrático autoconsciente e em decadência, as poucas cenas com camponeses a trabalhar refletem um distanciamento contemplativo que caracteriza também a grande parte das ligações de Ema. Existe sempre uma dimensão estética na representação dessas ligações e daquilo que isso gera. Isto é, há um lirismo na apresentação do universo de Vale Abraão que não só comanda toda a experiência do filme, como também espelha o tipo de discurso, de ação, de afeto, de contemplação do mundo, e de relação com as artes das personagens. Aparentemente contaminados, estes espaços distintos - o da narração formal e o da narrativapermanecem apesar de tudo diferenciados, mas convivendo em harmonia. A geografia e cartografia do Vale Abraão e o estilo lírico e romântico da narração não-focalizada do filme espelham o "estado de alma em balouço" da protagonista Ema, tal como ela se define a si mesma.

Exemplo do quarto tipo de relação entre personagem e espaço está em $\grave{A}$ flor do mar, na afirmação de Francesco Giarusso: "o mar, com os seus fluxos e refluxos, desencadeia as ações do filme, constituindo a sua principal força impulsionadora. . . É É o mar que reflete e revela as regiões submersas da alma das protagonistas, trazendo à tona aquilo que parecia já pertencer ao passado" (165). Ou seja, aqui o espaço goza de autonomia operativa na causalidade narrativa, para além de influir diretamente na esfera psicológica das personagens, desestabilizando a interioridade delas, redefinindo a sua motivação para a ação.

Finalmente, o quinto tipo de relação figura em $O$ rio do ouro, no qual a natureza adquire força e poder simbólicos, no sentido em que o espaço enclausura as personagens, representando neste filme a força de um destino trágico. A natureza manifesta-se em toda a sua pujança, impondo-se enquanto 
submundo de onde não se escapa: a banda sonora e as personagens alertam constantemente o espectador para a fatalidade, sempre agregada ao rio, que parece puxá-las para dentro de si. Ou seja, o espaço aqui apodera-se da trajetória e dos destinos das personagens, do espaço diegético (a organização da vida das personagens é ditada pelo rio), assim como também do tempo (o rio a acompanhar o fluir do tempo). A paisagem de $O$ rio do ouro é uma força centrípeta, unificadora, ensimesmada e inabalável. Esta se opõe à paisagem de Acto da primavera, por exemplo, no qual ela refloresce centrífuga e simultaneamente a vários níveis de formas distintas. No filme de Oliveira, as imagens tendem a ser na sua maioria quadros-vivos de inspiração naturalista que reforçam o estatuto da paisagem enquanto fonte de vida, solo e cenário de todas as ficções, mitos e crenças. Em Acto da Primavera e por oposição a $O$ rio do ouro, a natureza corresponde ao espaço aberto onde toda a criação (vida e arte) tem lugar.

\section{Uma contiguidade específica}

O conjunto de filmes aqui em análise reúne ficções de pendor documental variável. Vale Abraão, O rio do ouro, Veredas, À flor do mar e O fantasma inspiram-se menos diretamente no real do que os restantes filmes. Em todo o caso, independentemente das relações entre o real e da representação materializadas nestas películas, elas partilham um traço específico, pois atentam-se aos comportamentos, atitudes e orientações de personagens que habitam um espaço em concreto, sendo que se definem precisamente por habitarem esse espaço. E isto leva a que as personagens se tornem mais definidas, tanto quanto mais estes filmes atentam sobre a geografia (Natureza) ou a arquitetura (cidade), no sentido em que as trajetórias delas são desenhadas, invocadas, definidas pelos lugares que percorrem, tais como as ruas de Lisboa, a cordilheira transmontana, a planície alentejana, os edifícios destruídos, as margens do Douro e a praia.

Existe nestes filmes, portanto, uma contiguidade específica entre personagem e espaço: as personagens são criadas a partir do espaço e posteriormente mitificadas por via do processo de esteticização que ocorre quando a paisagem é edificada. Por este motivo, as personagens daqueles filmes não são desagregáveis da paisagem. Os realizadores vinculam a 
existência da personagem - a sua origem e a sua vivência em sociedade, a refletir jogos políticos e dinâmicas culturais concretas - à geografia. Assim, consolidam essa ligação projetando-a para uma dimensão estética, objetivamente reconhecível e sensualmente apreciável.

O filme que mais resiste a esta dinâmica é Veredas, no qual César Monteiro cria um corpo narrativo orgânico mesmo que fragmentário, ao reunir materiais heterogéneos de origens diferenciadas (contos populares portugueses, a história de Branca-Flor, excertos das Euménides de Ésquilo e textos da autoria de Maria Velho da Costa). Também ao nível do espaço, ele corta e cola: na cena com a deusa Atenas, por exemplo, ela surge em campo a recitar o texto de Ésquilo num monte rochoso transmontano, para um coro alentejano feminino, que the responde, em contra-campo, a partir do Alentejo. Vários tipos de continuidades são aqui subvertidos, provocando um efeito de estranheza e encantamento por via da forma desagregada e inverosímil com que o dispositivo da tragédia grega é apresentado. Em outras palavras, causa-se este efeito de estranheza pelo modo como um tempo mítico parece tocar numa realidade antropológica regional muito concreta, geograficamente localizável e posteriormente mitificada.

Neste contexto específico, este é o único filme em análise onde o espaço diegético é explicitamente intertextual e geograficamente desarticulado, ainda que sempre seja totalmente ancorado na geografia portuguesa. Assim, a inserção disruptiva da cena com a deusa Atenas vem expor uma dimensão retórica do espaço pelo modo como o filme reconstrói a paisagem portuguesa, restaurando-a na mitologia. O episódio experimental reforça aquilo que a película almeja desde o princípio: filmar um conto popular português de forma a resgatar uma memória cultural e social que vai sendo progressivamente mitificada.

\section{Movimento, paisagem e palavra}

De um ponto de vista formal, em Veredas, a câmara estática capta com calma a ação; há sempre muito ar em campo; o enquadramento dos planos invoca constantemente tableaux-vivants; a amplitude e a escala do espaço aberto contrastam com a dimensão da figura humana. Tudo isto parece instaurar no filme o Belo enquanto categoria estética. Na pintura de paisagem, o Belo está associado à ordem e ao regulado no pastoril; não há lugar para o caos, nem para 
elementos perturbadores ou abruptos. Ademais, historicamente as paisagens pintadas eram concebidas enquanto espaços habitados por figuras dos mitos clássicos ou alegorias (Brooks 110).

Neste sentido, parece-me que a insistência na dimensão pictórica da paisagem em Veredas ocorre precisamente para estabelecer uma ordenação e uma regulamentação, associadas a uma vivência social rural histórica, apesar da tal natureza fragmentária dos textos recitados e narrados. Tal vivência social rural está efetivamente ligada à tradição oral em que o filme ora se inscreve, ora vem estilhaçar.

Portanto, ao redesenhar estranhamente o território português para o projetar na tal dimensão contemplativa, estética e mitológica que é a da paisagem, César Monteiro concebe um espaço português-outro, onde a paisagem só encontra força narrativa semelhante na palavra. A narração em off é densa, hermética, eloquente, culta e refinada. A combinação de tantos textos de naturezas tão diferenciadas vem dificultar a apreensão deles. Mas, por outro lado, também surte um efeito encantatório, quase hipnótico, que conduz à contemplação daquela paisagem, porque no fundo a informa. O filme vive desta da tensão gerada pela permanente passagem de cenário a paisagem e vice-versa.

Vale Abraão e Trás-os-Montes são os filmes aqui em análise que mais diretamente se ligam a Veredas. O primeiro por apresentar um universo composto pelo espaço e pela palavra, elementos que se alimentam mutuamente, mas que em todo o caso convergem na personagem Ema, que detém a centralidade do filme, da palavra, e do campo. Mas o mundo de Vale Abraão retrata um mundo elitista, ao contrário do que faz o mundo de Veredas.

Já Trás-os-Montes partilha uma postura e um espaço. Nas palavras de Eduardo Prado Coelho, o filme procede a "uma deslocação no espaço que é simultaneamente uma deslocação no tempo. Por outras palavras, a geografia converte-se em memória: é toda uma imensa riqueza de símbolos, lendas, ritmos, que se vem inscrever - pastoralmente - sobre o corpo da terra" (62). De facto, a ligação entre o filme de Reis e Cordeiro e o filme de César é essencialista, até porque um descende do outro. Com apenas dois anos de diferença, João César Monteiro homenageia Trás-os-Montes em Veredas (1978), reproduzindo a panorâmica inicial horizontal sobre a paisagem transmontana. O filme de Reis e Cordeiro é homenagem e ponto de partida. Assim, Veredas parte de uma geografia convertida em memória, mas abre os 
limites do território geográfico, ampliando também a profusão e a natureza dos intertextos, levando a que o passado-memória e o tempo mitológico surjam intrincados, e levando até mesmo à existência de uma linha narrativa cuja ação decorre no pós-25 de Abril. Ou seja, existe uma dinâmica entre passados e presente na qual o mito - o tempo mítico - faz convocar o futuro, invocado pela presença frequente de caminhos sem fim, e confirmado pelo parto que decorre nos momentos finais do filme.

Esta simultaneidade de temporalidades surge na paisagem da ficção, cujo espaço também parece desdobrar-se ou, por momentos, contrair-se, por exemplo na cena com a deusa Atena. "Pensar a paisagem enquanto forma de tempo implica considerá-la algo em movimento e em mudança perenes. Daí a forma, quando se fala da forma da paisagem, não ser de todo algo fechado, completo, antes pelo contrário, um permanente formar-se," afirma Sonia Micelli (163). Este movimento constante que se encontra na paisagem de Veredas e na trajetória dos seus heróis caracteriza o retrato que César Monteiro faz de Portugal. Neste retrato, os espaços filmados operam como possíveis linhas de fuga que apontam para um único ponto, impossível.

Veredas reconfigura uma geografia nacional e entrecruza tempos históricos a partir das lições de cinema e de cultura que Reis e Cordeiro apresentam em Trás-os-Montes. Desta forma, César Monteiro oferece uma nova e mais radical chave de construção/contemplação da paisagem no cinema português que, como aqui se apresentou, subverte a vários níveis os conceitos de continuidade e contiguidade, sem perder a sua ancoragem no social, no histórico e no político.

\section{Obras Citadas}

Barthes, Roland. "Cher Antonioni." Cahiers du Cinéma, vol. 311, 1980, pp. 911.

Brooks, Isis. "Aesthetic Appreciation of Landscape." The Routledge Companion to Landscape Studies, editado por Peter Howard, Ian Thompson e Emma Waterton, Routledge, 2013, pp. 108-18.

Cauquelin, Anne. A invenção da paisagem, Edições 70, 2008.

Coelho, Eduardo Prado. Vinte anos de cinema português (1962-1982), Biblioteca Breve, 1983. 
Dias, Inês Sapeta. "Paisagem: sobre a reconfiguração cinematográfica da descrição da natureza." Cinema e filosofia: compêndio, editado por João Mário Grilo e Maria Irene Aparício, Colibri, 2014, pp. 283-301.

Giarusso, Francesco. "O labirinto e o espelho: o cinema de João César Monteiro.” LabCom.IFP, 2016. www.labcom-ifp.ubi.pt/ficheiros/

201604131812-201604_fgiarusso_labirintoespelho.pdf. Acesso em 17 janeiro 2017.

Lefebvre, Martin. "Between Setting and Landscape in the Cinema." Landscape and Film, editado por Martin Lefebvre. Routledge, 2006, pp. 19-59.

Lopes, Fernando, realizador. Belarmino. Produções Cunha Telles, 1964.

Miceli, Sonia. "De cartas e mapas: Livro, viagem e paisagem em Bernardo de Carvalho e Ruy Duarte de Carvalho.” Dissertação, U de Lisboa, 2016.

Monteiro, João César, realizador. À flor do mar. João César Monteiro, 1986.

—. Veredas. Instituto Português do Cinema, 1978.

Mozos, Manuel, realizador. Ruínas. O Som e a Fúria, 2009.

Oliveira, Manoel de, realizador. Acto da primavera. Manoel de Oliveira, 1963.

-. Vale Abraão. Madragoa, 1993.

Reis, António, e Margarida Cordeiro, realizadores. Trás-os-Montes. Centro Português de Cinema, 1976.

Rocha, Paulo, realizador. O rio do ouro. Suma Filmes, 1998.

-. Os verdes anos. Produções Cunha Telles, 1963.

Rodrigues, João Pedro, realizador. O fantasma. Amândio Coroado, 2000.

Rosário, Filipa, e Iván Villarmea Álvarez. “A paisagem no cinema: imagens para pensar o tempo através do espaço." Aniki: Revista Portuguesa da Imagem em Movimento, vol. 4, no. 1, 2017, pp. 55-63. 